\title{
Furin promotes epithelial-mesenchymal transition in pancreatic cancer cells via Hippo-YAP pathway
}

\author{
YOULI ZHANG $^{1 *}$, MENG ZHOU $^{1 *}$, HONG WEI $^{1}$, HAILANG ZHOU $^{1}$, JUNBO HE $^{1}$, YING LU $^{1}$, \\ DAWEI WANG ${ }^{1}$, BAODING CHEN $^{3}$, JIAN ZENG $^{2}$, WANXIN PENG ${ }^{2}$, FENGYI DU ${ }^{2}$, AIHUA GONG ${ }^{2}$ and MIN XU
}

\author{
Departments of ${ }^{1}$ Gastroenterology, Affiliated Hospital of Jiangsu University, ${ }^{2}$ Cell Biology, School of Medicine, and \\ ${ }^{3}$ Ultrasound Diagnosis, Affiliated Hospital of Jiangsu University, Jiangsu University, Zhenjiang, Jiangsu, P.R. China
}

Received November 1, 2016; Accepted February 20, 2017

DOI: 10.3892/ijo.2017.3896

\begin{abstract}
Furin, a well-characterized proprotein convertase, plays an important role in many diseases and links to tumor metastasis. However, the role of Furin in pancreatic cancer progression remains to be elucidated. In the present study, we found that Furin promotes the growth and the epithelial-mesenchymal transition (EMT) of pancreatic cancer cells. First, we found that Furin knockdown significantly inhibited proliferation, invasion and migration in BxPC3 and SW1990 cells, while Furin overexpression promoted the above behavior in PANC1 and PaTu8988 cells. Further evidence revealed that Furin knockdown resulted in the upregulation of E-cadherin (epithelial marker), and the downregulation of $\mathrm{N}$-cadherin and Vimentin (mesenchymal markers) in BxPC3 and SW1990 cells, whereas Furin overexpression remarkably led to the opposite effects in PANC1 and PaTu8988 cells. Furthermore, our data showed that Furin knockdown, Furin inhibitor D6R or overexpression significantly affected YAP phosphoration level and total YAP protein level, indicating that Furin was involved in Hippo-YAP pathway. It is suggested that Furin promotes epithelial-mesenchymal transition in pancreatic cancer cells probably via Hippo-YAP pathway and may be a potential target for anti-pancreatic cancer.
\end{abstract}

Correspondence to: Professor Aihua Gong, Department of Cell Biology, School of Medicine, Jiangsu University, 301 Xuefu Road, Zhenjiang, Jiangsu 212013, P.R. China

E-mail: ahg5@163.com

Dr Min Xu, Department of Gastroenterology, Affiliated Hospital of Jiangsu University, Jiangsu University, Zhenjiang, Jiangsu 212013 P.R. China

E-mail: peterxu1974@163.com

${ }^{*}$ Contributed equally

Key words: Furin, pancreatic cancer cells, epithelial-mesenchymal transition, YAP, D6R

\section{Introduction}

Pancreatic cancer is one of the most serious diseases, which lacks specific symptoms and progresses rapidly. It ranks the fourth in all cancer mortality rates. Despite decades of effort, the 5-year survival rate remains at only 5\% (1). Therefore, it is urgent to take a deep look of its biological characteristics, to insure that we can detect and diagnose pancreatic cancer in the early stage.

Epithelial-mesenchymal transition (EMT) is a developmental process where cells lose their epithelial features including loss of their sheet-like architecture, loss of polarity and develop a mesenchymal phenotype. As cells undergo EMT, they start expressing mesenchymal markers, such as $\mathrm{N}$-cadherin, Vimentin and downregulating E-cadherin (2-5). EMT was identified to be regulated by YAP through modulation of TGF $\beta$-Smad signaling (6). It is suggested that YAP/ Smad pathway potentially plays an important role in EMT.

Furin, a member of proprotein convertases (PCs), which belongs to a family of serine proteases capable of cleaving carboxyl-terminal of specific basic amino acid motifs and activating various precursor proteins $(7,8)$. These precursor proteins include growth factors and differentiation factors, receptors, adhesion molecules and enzymes like matrix metalloproteases (MMPs), which have been associated with different stages of tumor development, progression, vascularization and metastasis $(9,10)$. Previously, it has been reported that Furin is highly linked to various human primary tumors $(11,12)$ including skin tumor (13), colon tumor (14), head and neck (15) and breast (16) and ovarian cancer (17). Moreover, Furin can correctly cleave the TGF- $\beta$ precursor, which has been identified as a key regulator of EMT (18), indicating that Furin may link to EMT of tumor cells. However, the role of Furin in pancreatic cancer cells remains to be clarified.

In the present study, we found that Furin was critical for the growth and EMT of pancreatic cancer cells. Also, Furin upregulated total YAP protein level and downregulated YAP phosphoration level, indicating that Furin was involved in the YAP activation. Therefore, we speculate that Furin promotes epithelial-mesenchymal transition in pancreatic cancer cells probably via Hippo-YAP pathway. All these findings prove that Furin promotes EMT and may play a crucial role in pancreatic cancer progression. 


\section{Materials and methods}

Cell culture. The pancreatic cancer cells PaTu8988, BxPC3, PANC1 and SW1990 were obtained from the American Type Culture Collection (ATCC; Manassas, VA, USA) and the Cancer Cell Repository (Shanghai, China). Cells were maintained in Dulbecco's modified Eagle's medium (DMEM) with $10 \%$ fetal bovine serum (FBS) at standard cell culture conditions $\left(37^{\circ} \mathrm{C}, 5 \% \mathrm{CO}_{2}\right.$ in humidified incubator). DMEM, FBS and trypsin were purchased from Gibco (Carlsbad, CA, USA).

Plasmid construction. The construction of sh-Furin: the oligonucleotide sequences were inserted into the EcoRI and $A g e \mathrm{I}$ sites of the pLKO.1-TRC plasmid and ligated into the vector (Sigma-Aldrich, St. Louis, MO, USA). The targeting sequences for Furin was searched from Sigma-Aldrich and produced by Sangon Biotech Co., Ltd. (Shanghai, China). The oligo sequences of Furin shRNA included: Furin shRNA (F), CCG GGT GGC AAA GCG ACG GAC TAA ACT CGA GTT TAG TCC GTC GCT TTG CCA CTT TTT G and Furin shRNA (R), AAT TCA AAA AGT GGC AAA GCG ACG GAC TAA ACT CGA GTT TAG TCC GTC GCT TTG CCA C.

The construction of Flag-Furin: the full-length complementary DNA (cDNA) for human Furin was obtained from a cDNA library via polymerase chain reaction (PCR) amplificationusing primersFurin-all-F(5'-CCCAAGCTTATGGAGCTG AGGCCCTGGTTGC-3') and Furin-all-R (5'-CCGGAATTC GAGGGCGCTCTGGTCTTTGATAAA- $3^{\prime}$ ) and cloned into the EcoRI/HindIII site of p3xFLAG-Myc-CMV-24. The sequence was confirmed by DNA sequencing.

Transfection of the cell line. psPAx 2 and pMD2.G were co-transfected with sh-EGFP or sh-Furin into HEK293T cells using Lipofectamine 2000 (Invitrogen, Carlsbad, CA, USA). After $48 \mathrm{~h}$ the supernatants were collected and concentrated. BxPC3 and SW1990 cells were stably transfected with either sh-EGFP or sh-Furin plasmid. Cells were infected with $1 \times 10^{6}$ recombinant lentivirus transduction units in the presence of $8 \mathrm{mg} / \mathrm{ml}$ polybrene (Sigma-Aldrich). Cells were then cultured with puromycin (1:10,000 dilution) and the cells in blank group all became unviable.

PANC1 and PaTu8988 cells at $60-80 \%$ confluence were transfected with Lipofectamine 2000 reagent according to the manufacturer's instructions. The amount of vector and FlagFurin DNA used for transfection was $2 \mu \mathrm{g} /$ well in a 6-well plate, after cultured for $48-72 \mathrm{~h}$, the cells transfected were washed and harvested for further study.

D6R treatment. The pancreatic cancer cells BxPC3 were seeded at a final density of 100,000 cells/well on a 6 -well culture plates and the cells were plated at $30-50 \%$ confluence after $8 \mathrm{~h}$. Then, we added different doses of Furin inhibitor D6R. After treatment with D6R for $48 \mathrm{~h}$, cells were collected for different assays. The total cellular proteins were collected after treated with D6R for $72 \mathrm{~h}$.

Cell proliferation assay. To analyze the cell proliferation and the viability, we performed Cell Counting kit-8 (CCK-8). The pancreatic cancer cells were collected by trypsinization, and incubated in a 96-well plate at a final density of $2 \times 10^{3}$ cells/well for counting. A CCK-8 kit was added to assess the cells viability at $24,48,72,96$ and $120 \mathrm{~h}$ and the absorbance was finally determined at $490 \mathrm{~nm}$.

Colony formation assay. The colony formation assay was used to detect the anchorage-independent growth of the pancreatic cancer cells. The cells were plated at a final density of 500 cells/well. Each transfection group was seeded on 6-well culture plates. After the cells were incubated for 10-14 days, the cell colonies with $>50$ cells were counted then fixed with $4 \%$ paraformaldehyde and stained with crystal violet. Following the colony count a graph was prepared.

Scratch wound healing assay. To detect the ability of migration we incubated the cells at the density of $1 \times 10^{5}$ cells/well in a 24-well culture plate, and disrupted the confluent monolayer with a $10-\mu l$ pipette tip and then washed with phosphate-buffered saline (PBS) three times. The wounded monolayer was photographed over the following $24 \mathrm{~h}$. The migration ability of the cells was calculated by the ratio of the healing width at $24 \mathrm{~h}$ to the wound width at $0 \mathrm{~h}$.

Cell invasion and migration assay. The cells were incubated in the Transwell chambers which were coated with $4 \mu \mathrm{l} /$ well Matrigel (for an invasion assay; BD Biosciences) or without Matrigel (for a migration assay) in a serum-free DMEM according to the manufacturer's instruction and in the lower chambers 10\% FBS WAS added. At $24 \mathrm{~h}$, the cells that remained on the top of the filter were wiped off and the invasive cells on the lower chamber were stained and counted.

Real-time PCR. Total RNA was extracted using RNAiso Plus (Takara). Reverse transcription was performed using RevertAid First Strand cDNA Synthesis kit (Thermo Fisher Scientific) according to the manufacturer's specification. Realtime PCR was performed in triplicate in $20 \mu \mathrm{l}$ reactions with iQ SYBR ${ }^{\circledR}$ Premix Ex Taq ${ }^{\mathrm{TM}}$ Perfect Real-Time (Bio-Rad Laboratories, Hercules, CA, USA), 50 ng first strand cDNA and $0.2 \mu \mathrm{g}$ each primer. The primer pair used for the amplification of the human Furin gene was as follows: forward primer, 5'-CCAAAGACATCGGGAAACG-3' and reverse primer, 5'-TTAAACCCATCTGCGGAGTAG-3'; and GAPDH primer: forward, 5'-GGTGAAGGTCGGTGTGAACG-3' and reverse, 5'-CTCGCTCCTGGAAGATGGTG-3'. Samples were cycled once at $95^{\circ} \mathrm{C}$ for $2 \mathrm{~min}$, subjected to 35 cycles of $95^{\circ} \mathrm{C}, 56^{\circ} \mathrm{C}$ and $72^{\circ} \mathrm{C}$ for $30 \mathrm{sec}$ each. The relative mRNA content was calculated using the $2^{-\Delta \Delta C T}$ method with GAPDH as an endogenous control.

Western blot analysis. Cells were washed with PBS three times and lysed in $2 \mathrm{X}$ loading buffer on ice, then collected. Total cellular protein were boiling for $5 \mathrm{~min}$ to denature the fractions, and then separated equally on 10\% SDS-PAGE gels, transferred onto PVDF membranes. The membranes were blocked with 5\% skimmed milk for $1 \mathrm{~h}$ at room temperature. The membranes were incubated in the primary antibodies overnight at $4^{\circ} \mathrm{C}$, and the secondary horseradish peroxidase-conjugated antibodies for $1 \mathrm{~h}$ at room temperature. The bands were detected by enhanced chemiluminescence. The antibodies were rabbit anti-Furin (18413-1-AP; Proteintech, 
A

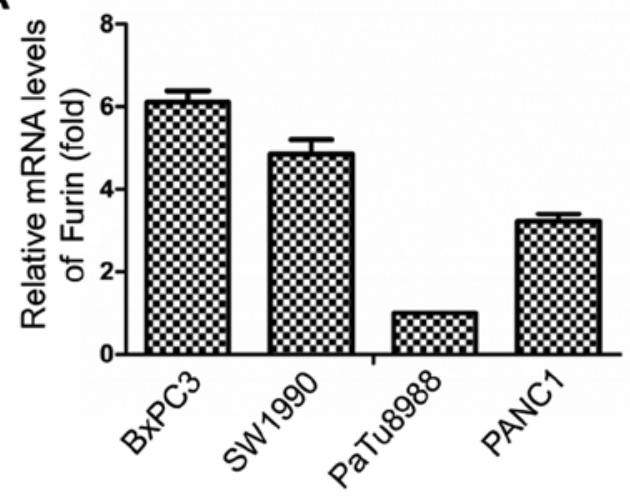

C

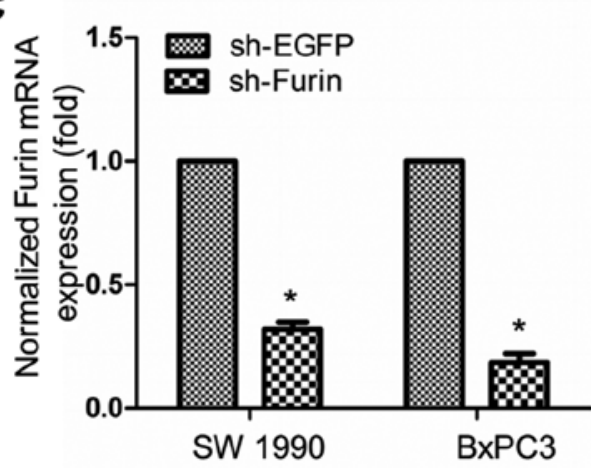

E

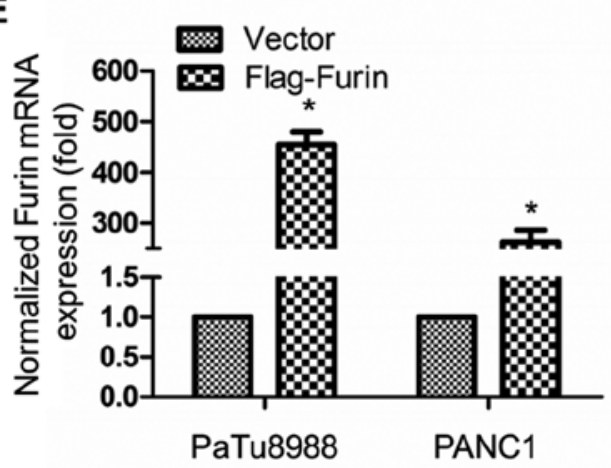

B

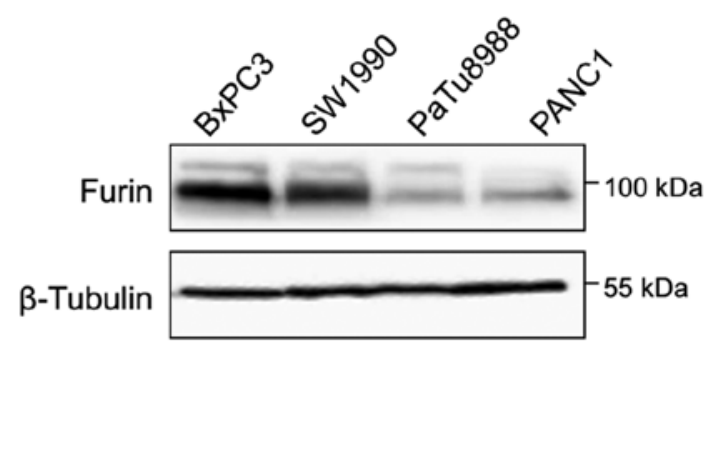

D

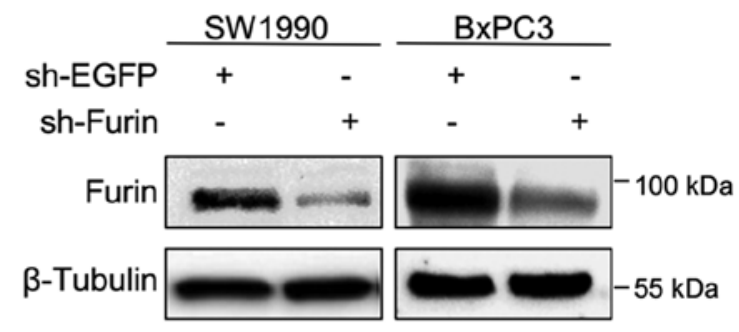

$\mathbf{F}$

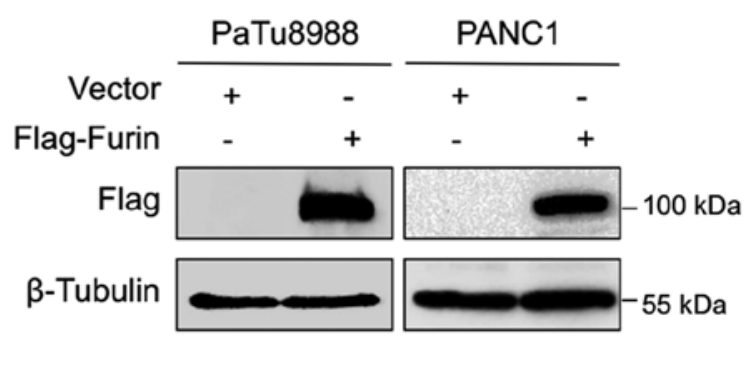

Figure 1. Detection of Furin expression in pancreatic cancer cells. Relative expression levels of (A) Furin mRNA and (B) protein were assessed in SW1990, BxPC3, PANC1 and PaTu8988 cells. Identification of shRNA-mediated Furin knockdown in SW1990 and BxPC3 cells by real-time-PCR and western blot analysis (C and D). GAPDH was used for normalization, the data are presented as the mean \pm SD. (Student's t-test: ${ }^{*} \mathrm{P}<0.05$ vs. sh-EGFP). The expression of Furin was verified in PANC1 and PaTu8988 cells, when transfected with vector or Flag-Furin plasmid (E and F). GAPDH was used for normalization, the data are presented as the mean $\pm \mathrm{SD}$. (Student's t-test: ${ }^{\mathrm{P}}<0.05$ vs. vector). All data were obtained from at least three independent experiments.

Rosemont, IL, USA), mouse anti- $\beta$-Tubulin (cat. no. 6181; Cell Signaling Technology, Danvers, MA, USA), mouse anti-Flag (cat. no. F1804; Sigma-Aldrich), rabbit anti-N-cadherin (cat. no. 13116; Cell Signaling Technology), rabbit anti-E-cadherin (cat. no. 3195; Cell Signaling Technology), rabbit anti-Vimentin (cat. no. 5741; Cell Signaling Technology), rabbit anti-YAP (cat. no. 8418; Cell Signaling Technology), rabbit anti-p-YAP (cat. no. 13619; Cell Signaling Technology), rabbit anti-Mob1 (cat. no. 13730; Cell Signaling Technology), rabbit anti-p-Mob1 (cat. no. 8699; Cell Signaling Technology).

\section{Results}

Furin expression varies in pancreatic cancer cells. We first used real-time PCR and western blotting to detect the expres- sion of Furin of pancreatic cancer cells. The data showed that the Furin mRNA and protein levels remained highly abundant in BxPC3 and SW1990 cells, while had weak expression in PANC1 and PaTu8988 cells (Fig. 1A and B). Next, we transfected BxPC3 and SW1990 cells with sh-EGFP or sh-Furin, the mRNA level of Furin was decreased by at least $70 \%$ in sh-Furin group compared with sh-EGFP group (Fig. 1C), as well as its protein level (Fig. 1D). Furin overexpression was also examined, and both mRNA and protein levels of Furin were significant upregulated in Flag-Furin group compared with vector group (Fig. 1E and F).

Furin promotes the growth of pancreatic cancer cells. To assess the effect of Furin on the cell growth, we used CCK- 8 assays to determine the relative proliferation rates in human pancreatic 
A

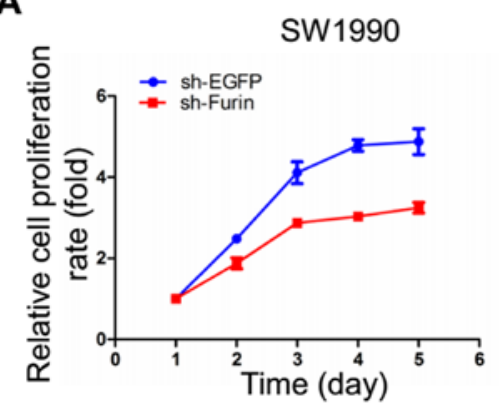

C

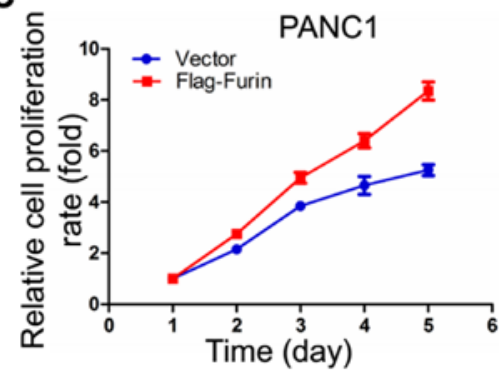

E
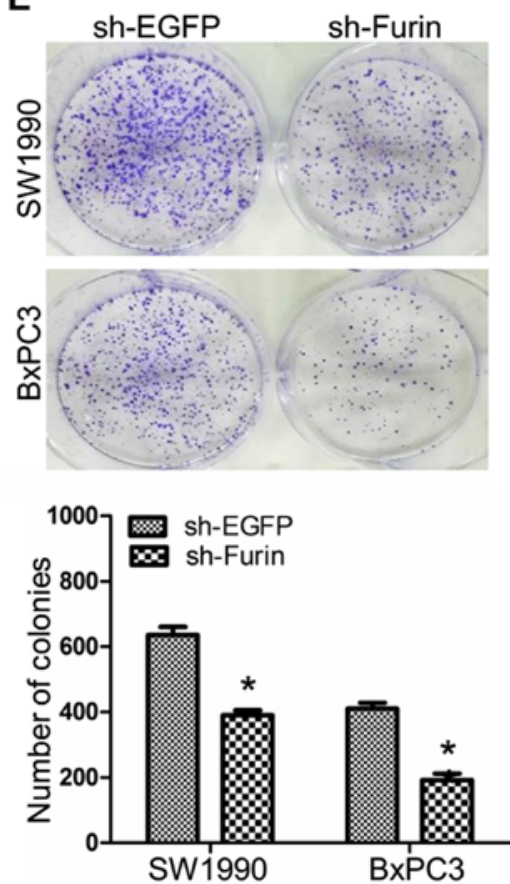

B

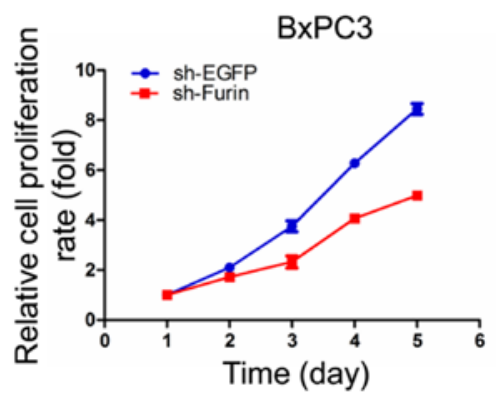

D

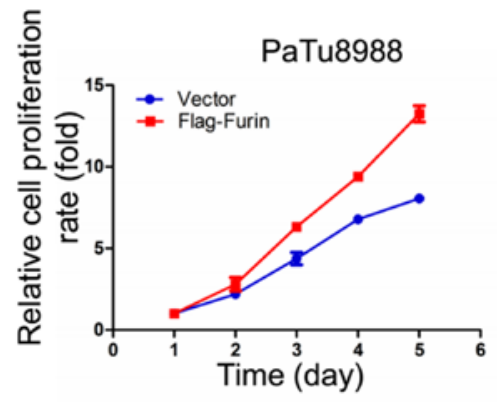

$\mathbf{F}$
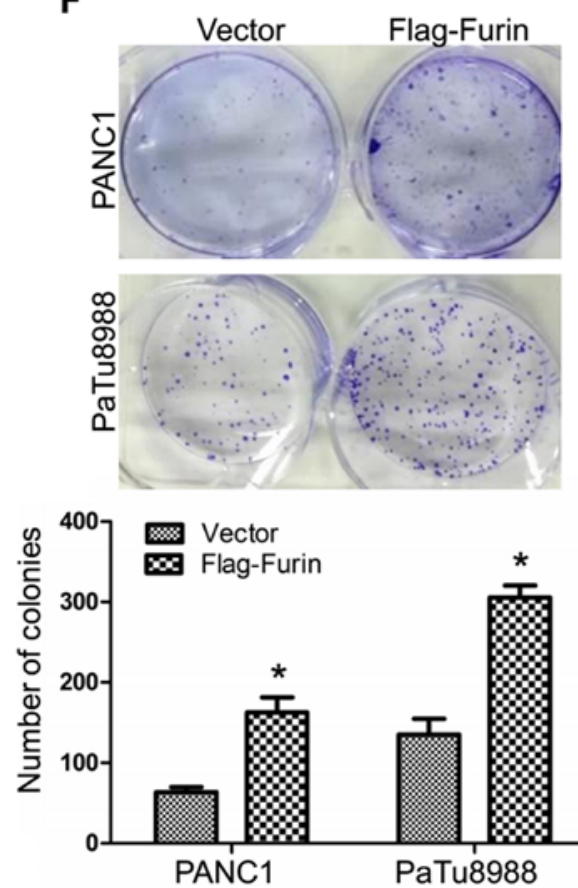

Figure 2. Furin promotes cell proliferation in pancreatic cancer cells. (A and B) CCK-8 assay showed that Furin knockdown inhibited BxPC3 and SW1990 cell growth rate, the data are presented as the mean $\pm \mathrm{SD}$; $(\mathrm{n}=3)$. (C and D) CCK-8 assay showed that Furin ovexpression promoted cell proliferation rate in PANC1 and PaTu8988 cells, the data are presented as the mean \pm SD $(n=3)$. (E) Colony forming assay showed that Furin knockdown inhibited BxPC3 and SW1990 cell anchorage-independent growth, the data are presented as the mean \pm SD (Student's t-test: * $<<0.05$ vs. sh-EGFP). (F) Colony forming assay showed that Furin ovexpression promoted PANC1 and PaTu8988 cell anchorage-independent growth, the data are presented as the mean \pm SD (Student's t-test: ${ }^{*} \mathrm{P}<0.05$ vs. vector). The data were obtained from at least three independent experiments.

cancer cells. As demonstrated by Fig. 2A and B, Furin knockdown decreased the relative rates of proliferation in BxPC3 and SW1990 cells, while Furin overexpression increased in PANC1 and PaTu8988 cells (Fig. 2C and D), indicating that Furin promoted the proliferation of pancreatic cancer cells. Colony forming assay provided additional support, and the data showed that the number of colonies were $635.5 \pm 17.5$ and $390 \pm 11$ in sh-EGFP and sh-Furin SW1990 cells, and 410 \pm 13 and 192 \pm 14 in sh-EGFP and sh-Furin BxPC3 cells (Fig. 2E), while the numbers of colonies were $64 \pm 5$ and $165 \pm 12$ in vector and Flag-Furin PANC1 cells, and $140 \pm 17$ and $304 \pm 18$ in vector and Flag-Furin PaTu8988 cells (Fig. 2F), suggesting that Furin promoted the ability of colony formation. All these data suggested that Furin promoted proliferation in pancreatic cancer cells.

Furin enhances migration of pancreatic cancer cells. To determine the roles of Furin in progress of pancreatic cancer cells, 
A

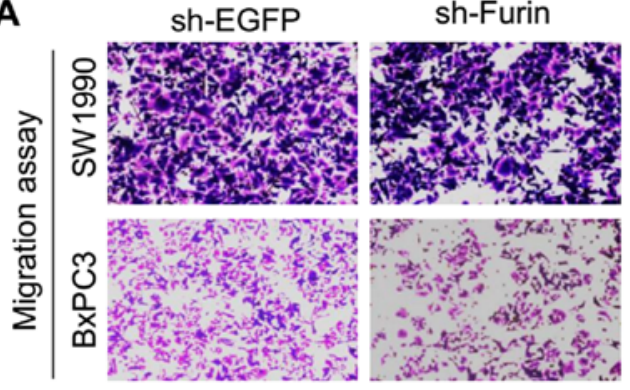

B

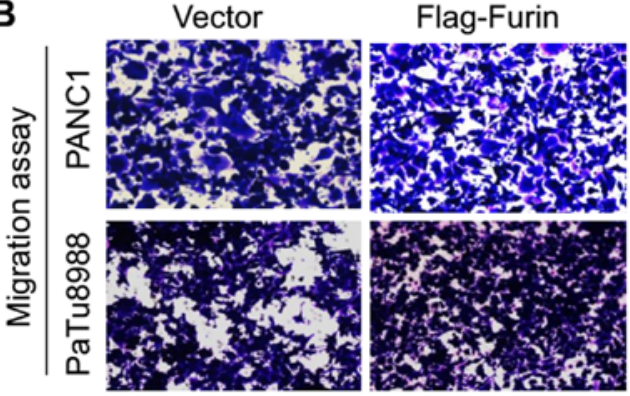

C
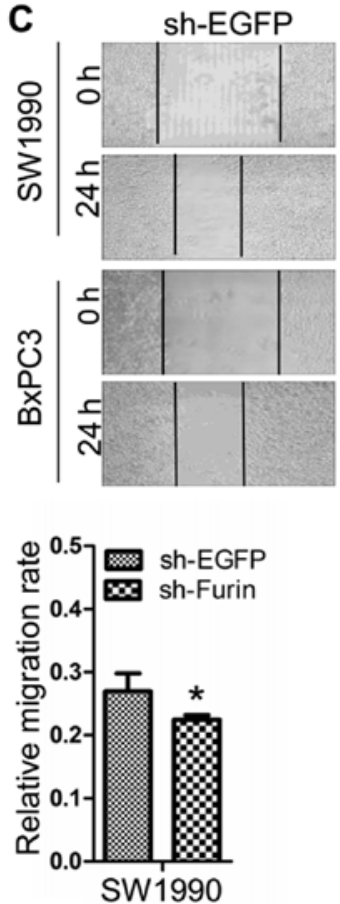
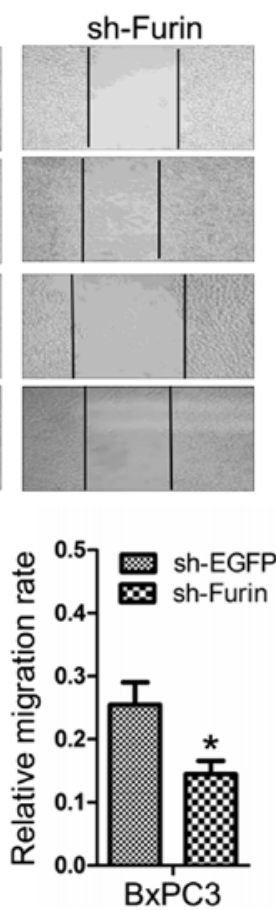
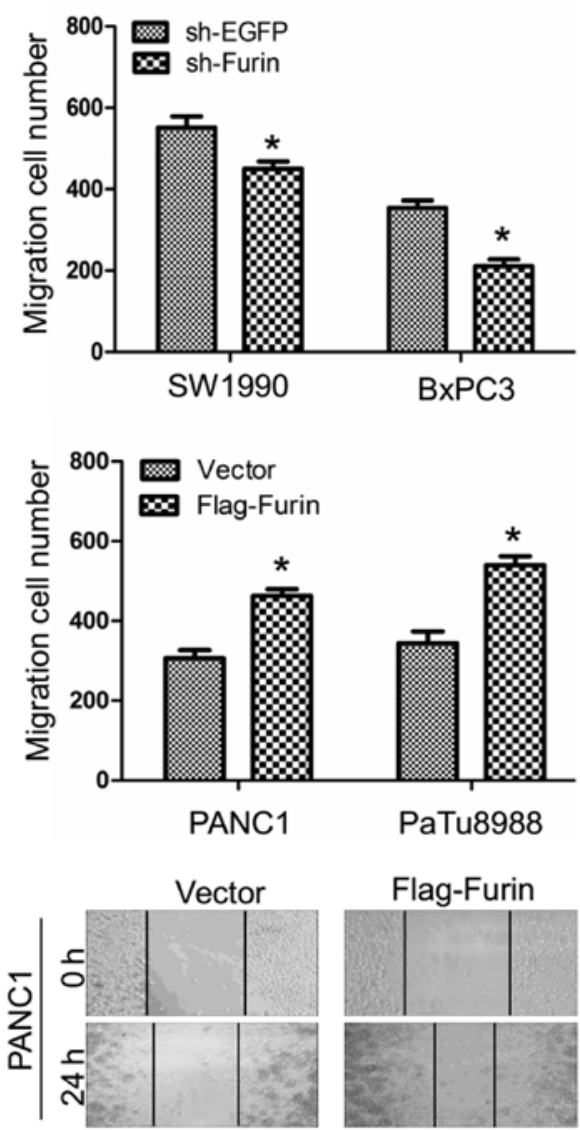

Flag-Furin
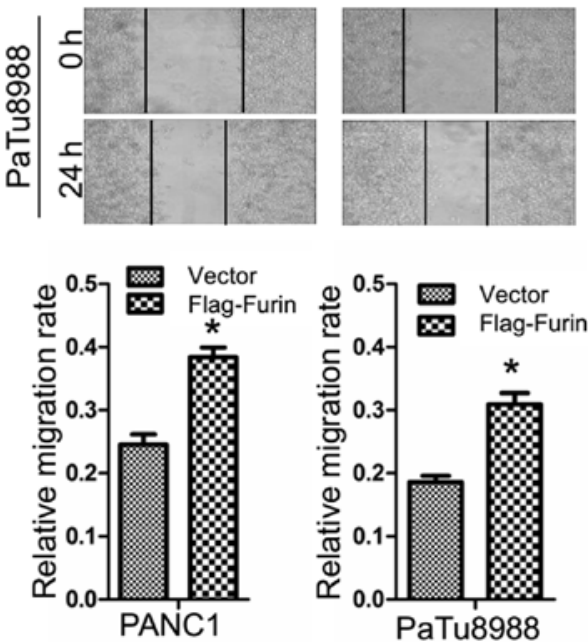

Figure 3. Furin promotes cell migration in pancreatic cancer cells. The migration changes was measured by Transwell migration assay (A and B) and wound healing assay (C), after transfected with sh-EGFP or sh-Furin plasmid in BxPC3 and SW1990 cells and vector or Flag-Furin plasmid in PANC1 and PaTu8988 cells, the data are presented as the mean $\pm \mathrm{SD}$ (Student's t-test: ${ }^{*} \mathrm{P}<0.05$ vs. sh-EGFP, ${ }^{*} \mathrm{P}<0.05$ vs. vector). The data were obtained from at least three independent experiments.

we used Transwell migration assays and wound healing assays to examine the ability of migration of pancreatic cancer cells. As showed in Fig. 3A and B, the numbers of migrated cells was $551 \pm 20$ and $450 \pm 13$ in sh-EGFP and sh-Furin SW1990 cells, and $354 \pm 13$ and $540 \pm 16$ in sh-EGFP and sh-Furin BxPC3 cells, while $309 \pm 15$ and $463 \pm 12$ in vector and Flag-Furin PANC1 cells, and $344 \pm 21$ and $211 \pm 12$ in vector and Flag-Furin PaTu8988 cells. Consistently, the migration rate was $0.27 \pm 0.02$ and $0.225 \pm 0.005$ in sh-EGFP and sh-Furin SW1990 cells, and $0.255 \pm 0.025$ and $0.145 \pm 0.015$ in sh-EGFP and sh-Furin BxPC3 cells, while $0.2455 \pm 0.0115$ and $0.384 \pm 0.011$ in vector and
Flag-Furin PANC1 cells, and $0.186 \pm 0.007$ and $0.3095 \pm 0.0125$ in vector and Flag-Furin PaTu8988 cells (Fig. 3C). The data suggested that Furin promoted migration of pancreatic cancer cells.

Furin activates the ability of invasion of pancreatic cancer cells. Then, we examined the effect of Furin on the invasive abilities of the pancreatic cancer cells using Transwell invasion assay. As shown in Fig. 4A and B, the number of invaded cells was $474 \pm 15$ and $238.5 \pm 12.5$ in sh-EGFP and sh-Furin SW1990 cells, and $320.5 \pm 14.5$ and $204 \pm 8$ in sh-EGFP and 
A

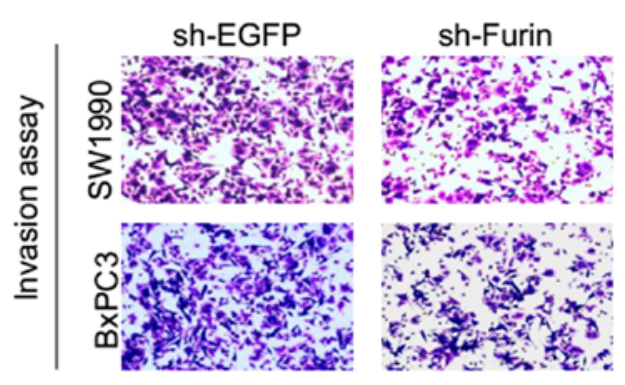

B
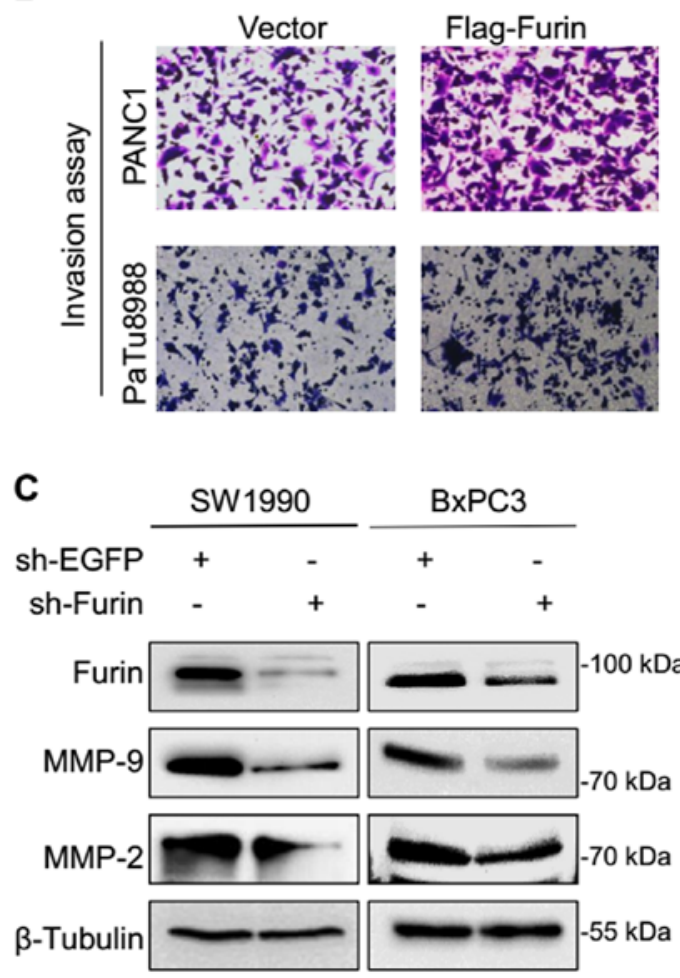
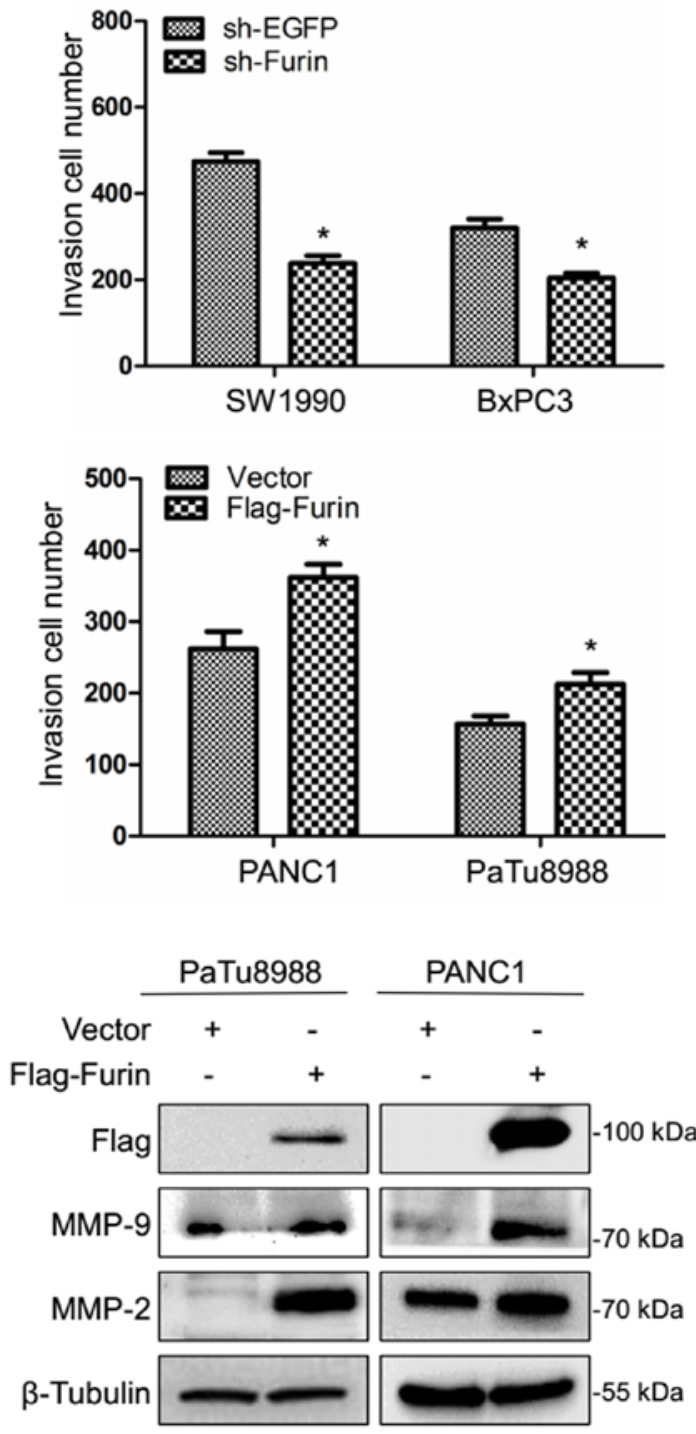

Figure 4. Furin promotes cell invasion in pancreatic cancer cells. The invasion changes were measured by Transwell invasion assay. After transfected with sh-EGFP or sh-Furin plasmid in BxPC3 and SW1990 cells (A) and vector or Flag-Furin plasmid in PANC1 and PaTu8988 cells (B), the data are presented as the mean \pm SD (Student's t-test: ${ }^{*} \mathrm{P}<0.05$ vs. sh-EGFP, ${ }^{*} \mathrm{P}<0.05$ vs. vector). The protein levels of MMP-2 and MMP-9 were measured by western blotting (C). The data were obtained from at least three independent experiments.

sh-Furin BxPC3 cells, while the number of invaded cells was $262 \pm 17$ and $362 \pm 13$ in vector and Flag-Furin PANC1 cells, and $157 \pm 8$ and $212.5 \pm 11.5$ in vector and Flag-Furin PaTu8988 cells suggesting that Furin promoted the invasion ability of pancreatic cancer cells.

As MMP-2 and MMP-9 possess the ability to hydrolyze components of the basement membrane and regulate various aspects of tumor growth and metastasis, we determined the effects of Furin on expression of MMP-2 and MMP-9. The results indicated that Furin overexpression led to the increase of the protein level of MMP-2 and MMP-9, and Furin knockdown resulted in the opposite effects (Fig. 4C). The above data suggested that Furin promoted the invasive ability of pancreatic cancer cells.

Furin induces EMT in pancreatic cancer cells. EMT is thought to be a key mechanism in which primary tumor cells are capable of metastasizing (19). To determine whether EMT is involved in Furin-induced migration and invasion, we first detected the expression of EMT markers at protein levels. The data showed that Furin knockdown resulted in the downregulation of $\mathrm{N}$-cadherin and Vimentin and in the upregulation of E-cadherin in SW1990 and BxPC3 cells. In PANC1 and PaTu8988 cells, Furin overexpression remarkably led to the opposite effects (Fig. 5A). Our data confirmed that Furin promoted EMT in pancreatic cancer cells.

Furin affects the Hippo-YAP pathway in pancreatic cancer cells. Previous studies identified that EMT can be regulated via Hippo-YAP signaling (20-22). To explore whether YAP is functional in Furin driving EMT in pancreatic cancer cells, we detected the expression of the relevant proteins in classic Hippo-YAP pathway, such as Mob1, p-Mob1, YAP and p-YAP. Our results revealed that Furin knockdown suppressed the expression of total YAP and p-Mob1, and upregulated p-YAP and Mob1 level, while Furin overexpression resulted in the opposite effects (Fig. 5B). These data suggested that Furin affected Hippo-YAP pathway in pancreatic cancer cells. 
A
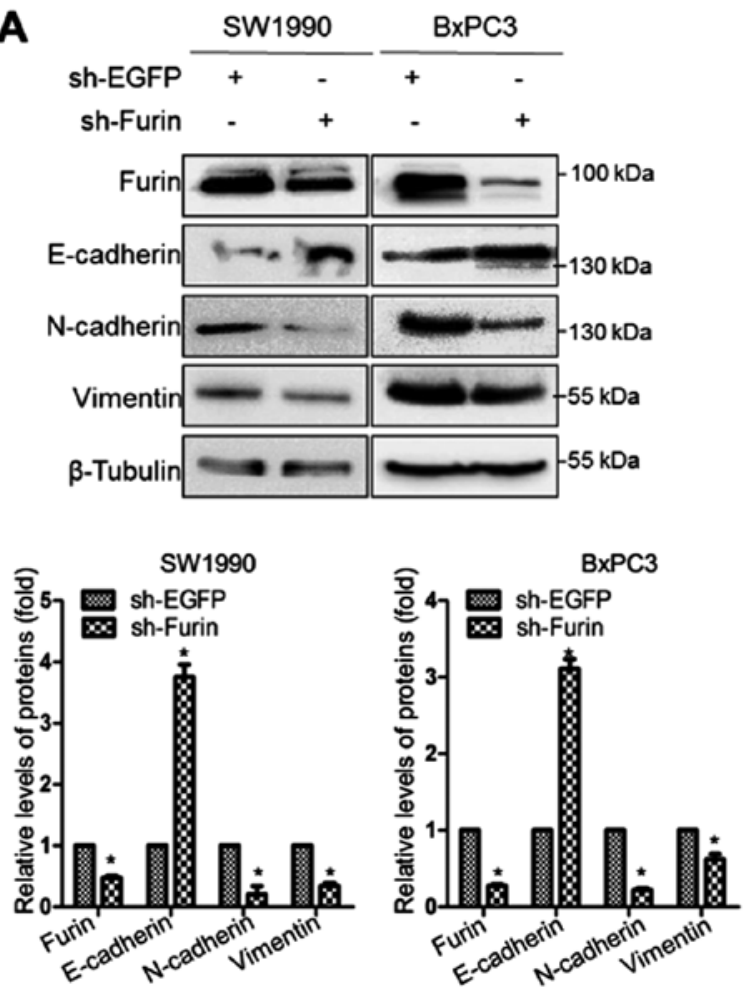

B

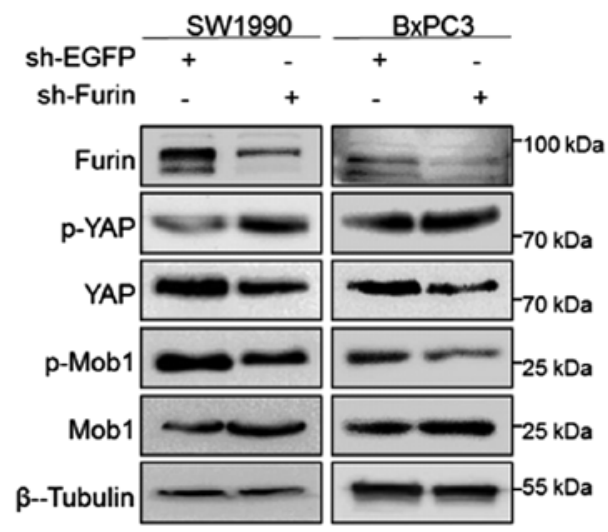

SW1990
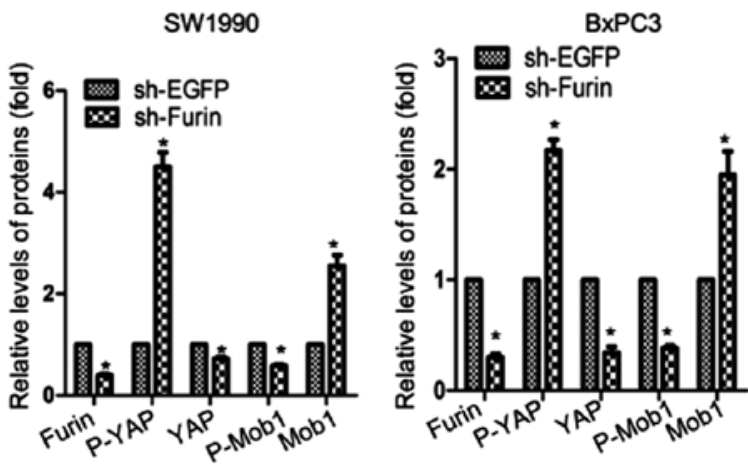
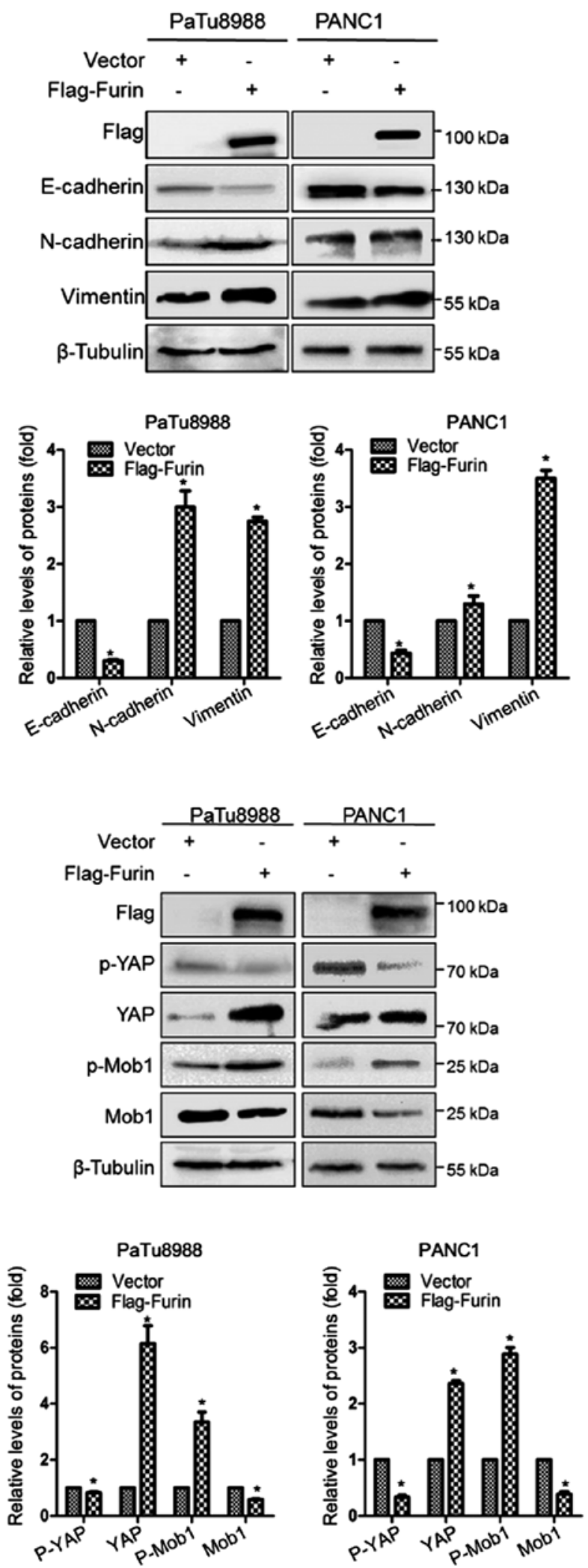

Figure 5. Furin affects EMT and Hippo-YAP signal pathway in pancreatic cancer cells. (A) The protein levels of E-cadherin, N-cadherin and Vimentin were measured by western blotting, after transfected with sh-EGFP or sh-Furin plasmid in BxPC3 and SW1990 cells and vector or Flag-Furin plasmid in PANC1 and PaTu8988 cells. (B) The protein levels of YAP, p-YAP, Mob1, p-Mob1 were measured by western blotting, after transfected with sh-EGFP or sh-Furin plasmid in BxPC3 and SW1990 cells and vector or Flag-Furin plasmid in PANC1 and PaTu8988 cells. The histograms show the gray intensity analyses to the bands of western blotting, and the data are presented as the mean $\pm \mathrm{SD}$ (Student's t-test: ${ }^{*} \mathrm{P}<0.05$ vs. sh-EGFP, $\mathrm{P}<0.05$ vs. vector). The data were obtained from at least three independent experiments.

Furin inhibitor D6R suppresses the proliferation, migration and invasion of BXPC3 cells. Furin inhibition seems to be a logical route to inhibiting the activation of its substrates, many of which are essential components of the invasive/metastatic 
A

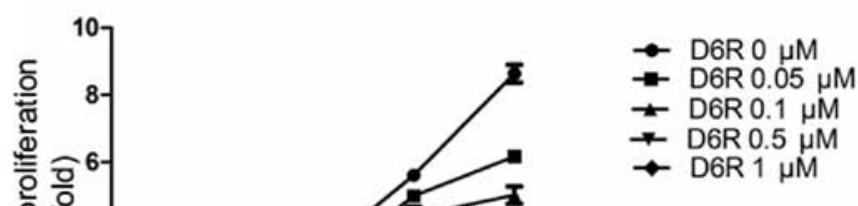

B
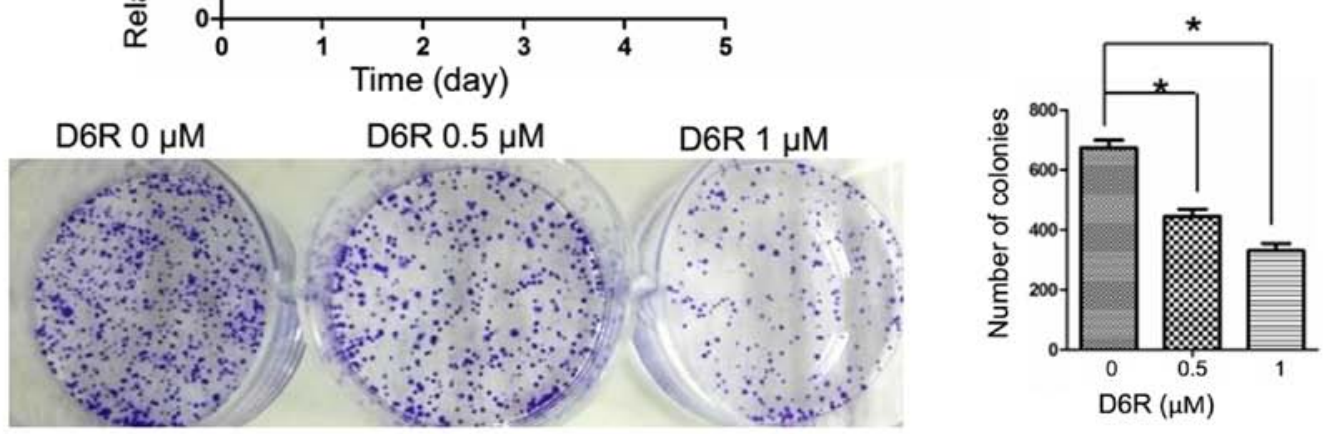

C
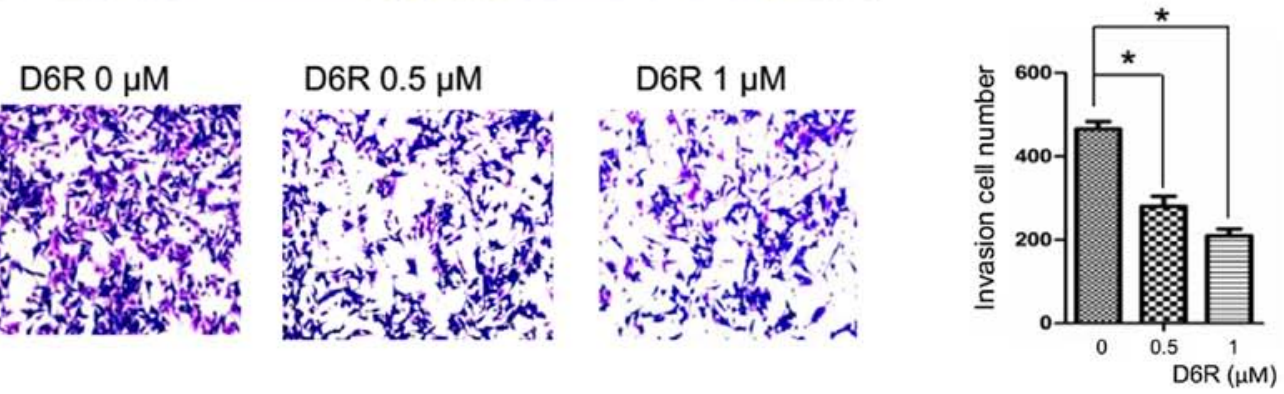

D
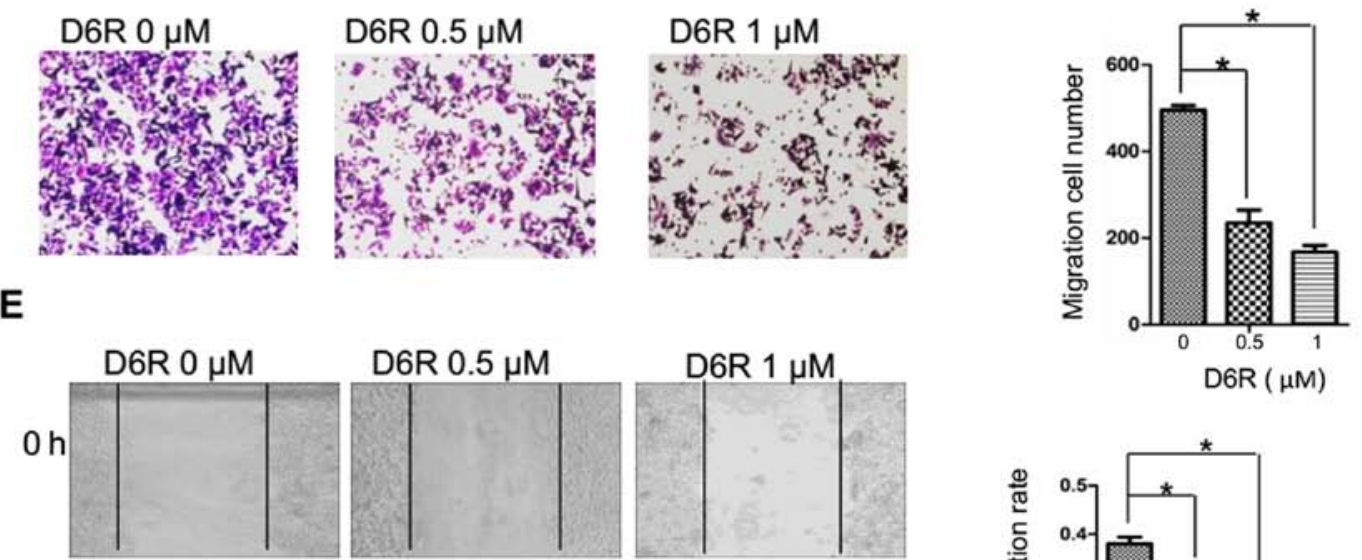

D6R $0.5 \mu \mathrm{M}$
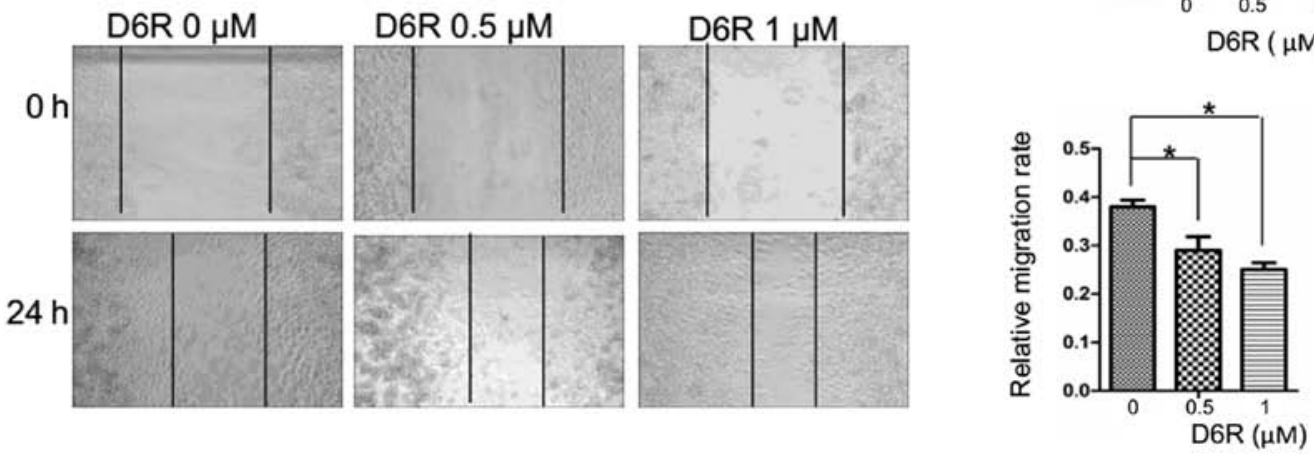

Figure 6. Furin inhibitor D6R prohibits the ability of proliferation, migration and invasion in BxPC3 cells. (A) CCK-8 assay showed that D6R inhibited BxPC3 cell growth rate and it was concentration dependent. (B) Anchorage-independent growth was evaluated by colony formation assay, the data are presented as the mean \pm SD (Student's t-test: ${ }^{*} \mathrm{P}<0.05$ vs. D6R-free group). (C) The ability of invasiveness was detected by Transwell assay, the data are presented as the mean \pm SD (Student's t-test: * $\mathrm{P}<0.05$ vs. D6R-free group). (D and E) The ability of migration was detected by Transwell assay and wound healing assay, the data are presented as the mean \pm SD (Student's t-test: ${ }^{*} \mathrm{P}<0.05$ vs. D6R-free group). The data were obtained from at least three independent experiments.

cascade (e.g. TGF- $\beta$ and MT-MMPs). The above data confirm that the expression levels of Furin affected EMT probably via Hippo-YAP pathway in pancreatic cancer cells. It is worth assessing whether the activity of Furin similarly affects their growth and EMT. Therefore, we first treated BxPC3 cells with different doses of Furin inhibitor D6R (0, 0.05, 0.1, 0.5 and $1 \mu \mathrm{M})$. The data indicated that D6R significantly inhibited the cell proliferation in dose-dependent manner (Fig. 6A), and the half maximal inhibitory concentration $\left(\mathrm{IC}_{50}\right)$ of $\mathrm{D} 6 \mathrm{R}$ is between 0.5 and $0.6 \mu \mathrm{M}$. Therefore, the concentration of 0 , 
A

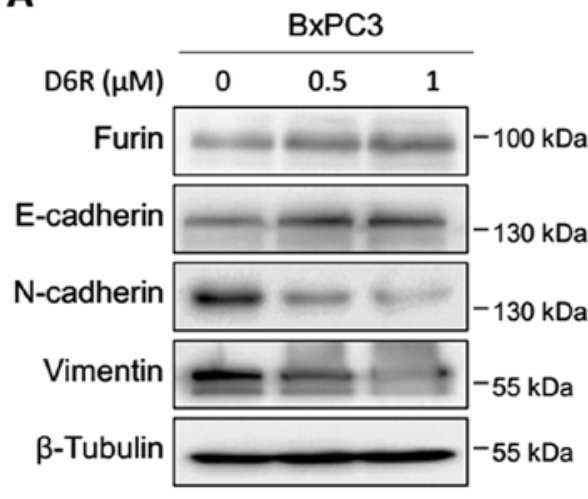

B

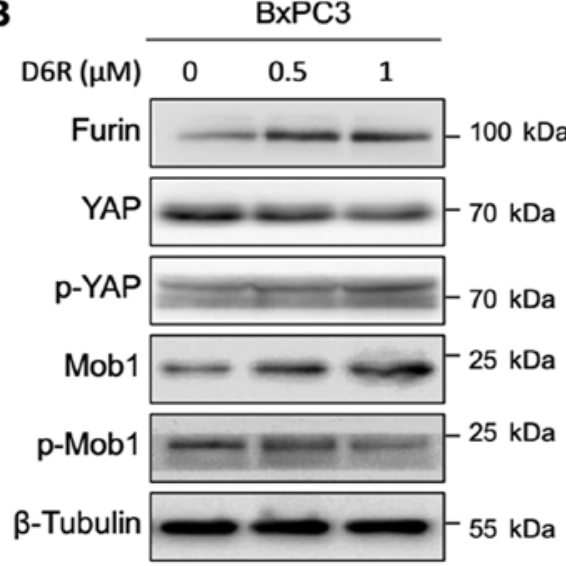

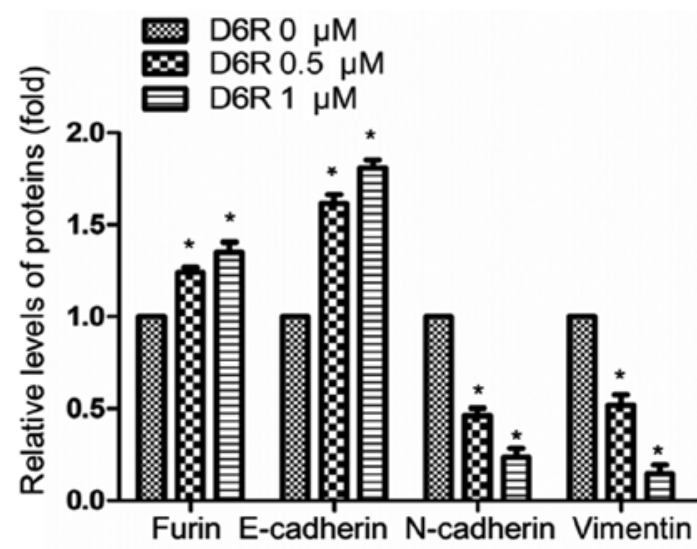

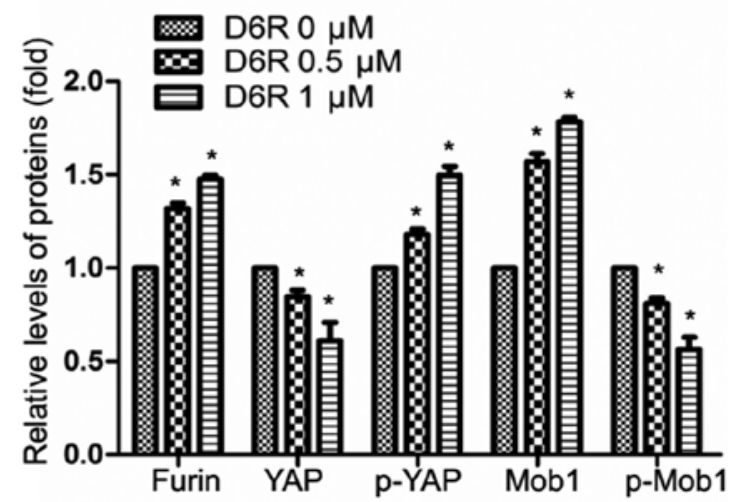

Figure 7. Furin inhibitor D6R affects the EMT and Hippo-YAP pathway in BxPC3 cells. (A) The protein levels of E-cadherin, N-cadherin and Vimentin were measured by western blotting. (B) The protein levels of YAP, p-YAP, Mob1, p-Mob1 were measured by western blotting. The histograms show the gray intensity analyses to bands of western blotting, and the data are presented as the mean \pm SD (Student's t-test: "P<0.05 vs. D6R-free group). The data were obtained from at least three independent experiments.

0.5 and $1 \mu \mathrm{M}$ was selected for further study. We found that compared to the D6R-free group, the abilities of proliferation, migration and invasion were significantly suppressed in the D6R groups (Fig. 6B-E), indicating that the activity of Furin actually affects the biological behavior of pancreatic cancer cells.

Furin inhibitor D6R affects EMT and Hippo-YAP pathway in pancreatic cancer cells. Next, we examined the effects of D6R on EMT and Hippo-YAP pathway. As shown in Fig. 7A, D6R resulted in the downregulation of $\mathrm{N}$-cadherin, Vimentin and in the upregulation of E-cadherin. Also, D6R resulted in the downregulation of total YAP, p-Mob1 and in the upregulation of p-YAP, Mobl (Fig. 7B). It is suggested that Furin inhibitor D6R affects EMT and Hippo-YAP pathway in pancreatic cancer cells.

\section{Discussion}

We identified that Furin functions as an oncogene in pancreatic cancer cells. Furin promotes proliferation, migration and invasion in pancreatic cancer cells. Importantly, Furin promotes EMT probably via the Hippo-YAP signal pathway.

There is evidence connecting Furin with tumorigenicity of a wide spectrum of human tumors. Furin promotes cell proliferation, tumorigenicity and invasiveness of head and neck squamous cell carcinoma (HNSCC) cells in vitro and in vivo $(11,15)$. Increasing Furin expression enhanced skin tumor development and growth (13). Inhibition of Furin suppressed the IGF-1 receptor which affected IRS-1 and Akt phosphorylation and showed a significantly reduced ability to form liver metastases in vivo (14). In this study, we find that Furin activates oncogenic activities such as the proliferation and the ability of colony formation in pancreatic cancer cells are consistent with previous studies in other tumors and further support its oncogenic potential.

Furthermore, Furin can process a group of notorious molecules involved directly or indirectly in tumor growth and progression, such as vascular endothelial growth factor (VEGF), insulin-like growth factor-1 receptor (IGF-1R), transforming growth factor- $\beta$ (TGF- $\beta$ ), insulin-like growth factor 2 (IGF-2) and membrane type 1 matrix metalloproteinase (MT1-MMP), which contributes to aggression and metastatic potential of cancer cells (23-27). Accumulating evidence reveal that Furin-processed substrate molecules, including TGF- $\beta$ and MT1-MMP, are critical for enhancing invasion metastasis and promoting EMT $(24,25)$. Hence, it would be logical to conclude that Furin played a central role in EMT. In the present study, we proved that Furin knockdown resulted in downregulation of N-cadherin and Vimentin, and upregulation of E-cadherin while Furin overexpression remarkably led to the opposite effects. Moreover, the fact that Furin enhanced 
the ability of migration and invasion in pancreatic cancer cells, was consistent with previous studies and further supported the significant role of Furin in EMT. As a precursors cleaved by Furin, some investigations showed that $\mathrm{N}$-cadherin rendered a substantial decrease in cell migration (28), whereas other studies linked the NCAD activated by Furin to intestinal tumorigenesis (29). These conflicting data show that Furin function and/or expression in cancer cells varies in a tumorspecific fashion. It is reported that Furin activated NCAD at site RQKR\DW161 and a second putative PC-processing site RIRSDR $\downarrow D K 189$ located in the first extracellular domain. Cleavage at the second site would inactive NCAD because of the loss of the critical Trp161 (30). We surmised that the activated/inactivated NCAD exist in a balance. In our model, we speculated that Furin may mainly activate NCAD in pancreatic cancer cells. Furthermore, Furin activated precursors implicated in epithelial to mesenchymal transition (31), an ECAD-to-NCAD transition, such as TGF- $\beta$ (25).

YAP, as a direct downstream effector of the Hippo pathway, is found to play an important role in EMT (20). A previous study confirms that YAP and KRAS converge on the FOS to regulate EMT (21). YAP and TAZ likely together with the co-factor Tead 2 provoke the induction of EMT $(20,22)$. These observations suggested that YAP1 interacted with specific transcription factors to regulate EMT. Our results demonstrated conclusively that Furin-induced regulation of EMT accompanied with the alterations of YAP phosphoration level and total YAP protein level. This effect strongly suggests that Furin might have a role in cleaving the upstream proteins of Hippo-YAP pathway. For example, Furin is probably involved in the activation of growth factors and adhesion molecules which may influence the subcellular localization of YAP, such as TGF- $\beta$ and E-cadherin $(28,32)$. The possible divergence in function of Furin leads to a link with YAP. However, further investigations are required to elucidate the role of Furin processing in the regulation of EMT via Hippo-YAP pathway.

In conclusion, inhibition or depletion of Furin results in a marked reduction of proliferation, migration and invasiveness of pancreatic cancer cells. Our results indicate that Furin promotes EMT in pancreatic cancer cells may be through affecting the Hippo-YAP pathway. Further study is needed on the mechanisms of Furin. Taken together, this information indicates that inhibition or depletion of Furin may be a viable route to ameliorate the malignant phenotype of pancreatic cancer cells.

\section{Acknowledgements}

The present study was supported by grants from the National Natural Science Foundation of China (nos. 81672402, 81472333 and 81372718) and the Natural Science Foundation of Jiangsu Province (BK20131247).

\section{References}

1. Wolfgang CL, Herman JM, Laheru DA, Klein AP, Erdek MA, Fishman EK and Hruban RH: Recent progress in pancreatic cancer. CA Cancer J Clin 63: 318-348, 2013.

2. Thiery JP, Acloque H, Huang RY and Nieto MA: Epithelialmesenchymal transitions in development and disease. Cell 139: 871-890, 2009.
3. Kalluri R and Weinberg RA: The basics of epithelial-mesenchymal transition. J Clin Invest 119: 1420-1428, 2009.

4. Rasheed ZA, Yang J, Wang Q, Kowalski J, Freed I, Murter C, Hong SM, Koorstra JB, Rajeshkumar NV, He X, et al: Prognostic significance of tumorigenic cells with mesenchymal features in pancreatic adenocarcinoma. J Natl Cancer Inst 102: 340-351, 2010.

5. Dangi-Garimella S, Krantz SB, Shields MA, Grippo PJ and Munshi HG: Epithelial-mesenchymal transition and pancreatic cancer progression. In: Pancreatic Cancer and Tumor Microenvironment. Grippo PJ and Munshi HG (eds). Trivandrum (India): Transworld Research Network; 2012. Chapter 5. Available from: https://www.ncbi.nlm.nih.gov/books/NBK98932/.

6. Zhang H, von Gise A, Liu Q, Hu T, Tian X, He L, Pu W, Huang X, He L, Cai CL, et al: Yap1 is required for endothelial to mesenchymal transition of the atrioventricular cushion. J Biol Chem 289: 18681-18692, 2014

7. Molloy SS, Bresnahan PA, Leppla SH, Klimpel KR and Thomas G: Human furin is a calcium-dependent serine endoprotease that recognizes the sequence Arg-X-X-Arg and efficiently cleaves anthrax toxin protective antigen. J Biol Chem 267: 16396-16402, 1992.

8. Walker JA, Molloy SS, Thomas G, Sakaguchi T, Yoshida T, Chambers TM and Kawaoka Y: Sequence specificity of furin, a proprotein-processing endoprotease, for the hemagglutinin of a virulent avian influenza virus. J Virol 68: 1213-1218, 1994.

9. Seidah NG, Mayer G, Zaid A, Rousselet E, Nassoury N, Poirier S, Essalmani R and Prat A: The activation and physiological functions of the proprotein convertases. Int $\mathrm{J}$ Biochem Cell Biol 40: 1111-1125, 2008.

10. Artenstein AW and Opal SM: Proprotein convertases in health and disease. N Engl J Med 365: 2507-2518, 2011.

11. López de Cicco R, Bassi DE, Zucker S, Seidah NG and KleinSzanto AJ: Human carcinoma cell growth and invasiveness is impaired by the propeptide of the ubiquitous proprotein convertase furin. Cancer Res 65: 4162-4171, 2005.

12. Scamuffa N, Sfaxi F, Ma J, Lalou C, Seidah N, Calvo F and Khatib AM: Prodomain of the proprotein convertase subtilisin/ kexin Furin (ppFurin) protects from tumor progression and metastasis. Carcinogenesis 35: 528-536, 2014.

13. Fu J, Bassi DE, Zhang J, Li T, Nicolas E and Klein-Szanto AJ: Transgenic overexpression of the proprotein convertase furin enhances skin tumor growth. Neoplasia 14: 271-282, 2012.

14. Scamuffa N, Siegfried G, Bontemps Y, Ma L, Basak A, Cherel G, Calvo F, Seidah NG and Khatib AM: Selective inhibition of proprotein convertases represses the metastatic potential of human colorectal tumor cells. J Clin Invest 118: 352-363, 2008.

15. Bassi DE, Mahloogi H, Lopez De Cicco R and Klein-Szanto A: Increased furin activity enhances the malignant phenotype of human head and neck cancer cells. Am J Pathol 162: 439-447, 2003.

16. Cheng M, Watson PH, Paterson JA, Seidah N, Chrétien M and Shiu RP: Pro-protein convertase gene expression in human breast cancer. Int J Cancer 71: 966-971, 1997.

17. Page RE, Klein-Szanto AJ, Litwin S, Nicolas E, Al-Jumaily R, Alexander P, Godwin AK, Ross EA, Schilder RJ and Bassi DE: Increased expression of the pro-protein convertase furin predicts decreased survival in ovarian cancer. Cell Oncol 29: 289-299, 2007.

18. Bax NA, van Oorschot AA, Maas S, Braun J, van Tuyn J, de Vries AA, Groot AC and Goumans MJ: In vitro epithelial-tomesenchymal transformation in human adult epicardial cells is regulated by TGF $\beta$-signaling and WT1. Basic Res Cardiol 106: 829-847, 2011.

19. Gonzalez DM and Medici D: Signaling mechanisms of the epithelial-mesenchymal transition. Sci Signal 7: re8, 2014.

20. Overholtzer M, Zhang J, Smolen GA, Muir B, Li W, Sgroi DC, Deng CX, Brugge JS and Haber DA: Transforming properties of YAP, a candidate oncogene on the chromosome 11q22 amplicon. Proc Natl Acad Sci USA 103: 12405-12410, 2006.

21. Shao DD, Xue W, Krall EB, Bhutkar A, Piccioni F, Wang X, Schinzel AC, Sood S, Rosenbluh J, Kim JW, et al: KRAS and YAP1 converge to regulate EMT and tumor survival. Cell 158: 171-184, 2014. 
22. Diepenbruck M, Waldmeier L, Ivanek R, Berninger P, Arnold P, van Nimwegen E and Christofori G: Tead2 expression levels control the subcellular distribution of Yap and Taz, zyxin expression and epithelial-mesenchymal transition. J Cell Sci 127: 1523-1536, 2014

23. Pei D and Weiss SJ: Furin-dependent intracellular activation of the human stromelysin-3 zymogen. Nature 375: 244-247, 1995.

24. Yana I and Weiss SJ: Regulation of membrane type-1 matrix metalloproteinase activation by proprotein convertases. Mol Biol Cell 11: 2387-2401, 2000.

25. Dubois CM, Blanchette F, Laprise MH, Leduc R, Grondin F and Seidah NG: Evidence that furin is an authentic transforming growth factor-beta1-converting enzyme. Am J Pathol 158: 305-316, 2001.

26. Duguay SJ, Jin Y, Stein J, Duguay AN, Gardner P and Steiner DF: Post-translational processing of the insulin-like growth factor-2 precursor. Analysis of O-glycosylation and endoproteolysis. J Biol Chem 273: 18443-18451, 1998.

27. Lopez de Cicco R, Watson JC, Bassi DE, Litwin S and KleinSzanto AJ: Simultaneous expression of furin and vascular endothelial growth factor in human oral tongue squamous cell carcinoma progression. Clin Cancer Res 10: 4480-4488, 2004.
28. Maret D, Gruzglin E, Sadr MS, Siu V, Shan W, Koch AW, Seidah NG, Del Maestro RF and Colman DR: Surface expression of precursor $\mathrm{N}$-cadherin promotes tumor cell invasion. Neoplasia 12: 1066-1080, 2010.

29. Sun X, Essalmani R, Seidah NG and Prat A: The proprotein convertase $\mathrm{PC} 5 / 6$ is protective against intestinal tumorigenesis: In vivo mouse model. Mol Cancer 8: 73, 2009.

30. Maret D, Sadr MS, Sadr ES, Colman DR, Del Maestro RF and Seidah NG: Opposite roles of furin and PC5A in N-cadherin processing. Neoplasia 14: 880-892, 2012.

31. Chen X, Halberg RB, Burch RP and Dove WF: Intestinal adenomagenesis involves core molecular signatures of the epithelial-mesenchymal transition. J Mol Histol 39: 283-294, 2008.

32. Bassi DE, Mahloogi $\mathrm{H}$ and Klein-Szanto AJ: The proprotein convertases furin and PACE4 play a significant role in tumor progression. Mol Carcinog 28: 63-69, 2000. 